\title{
Forest History - Past, Present, and Future
}

The Forest History Association of British Columbia was founded in 1982 with the objectives of saving, recording and increasing the awareness and interest in British Columbia forest history.

At present we have approximately 225 members who work in industry, government and academia who are located in all corners of $\mathrm{BC}$, the rest of Canada and the US, and Europe.

In recent years we have published three books:

- Tom Wright - Recollections of a Pioneer Forester and Tree Farmer

- Frederick Davidson Mulholland The Father of Sustained Yield Forestry in British Columbia

- Alan Orr-Ewing - Father of Forest Geneticst in British Columbia

- Collected oral histories of more than 75 people ranging from Ministry of Forests and industry sector executives to cooks and manual workers who have all contributed to the story of the forest sector.

At present, we have an oral history program on the Aleza Lake Forest Experiment Station near Prince George. We hope to complete this project with typed transcript by the end of 2013.

- Completed a major upgrade to our Web site $<$ fhabc.org $>$

The Web site not only provides access to our organization and activities, but also gives access to publication lists and links to other forestry organizations and sites.

We also publish a quarterly Newsletter. All copies of our past Newsletters can be obtained through our Web site.

As well, we hold an Annual Meeting alternating between the Coast and the Interior in an attempt to clearly identify the Association as a province-wide organization. To date, our Interior meetings have been held in Kamloops, Prince George and Vernon. The Annual Meeting consists normally of a short business meeting, a field trip to a local museum, archive, or local point of interest and a dinner with a guest speaker. We usually have 15 to 20 people attending each event.

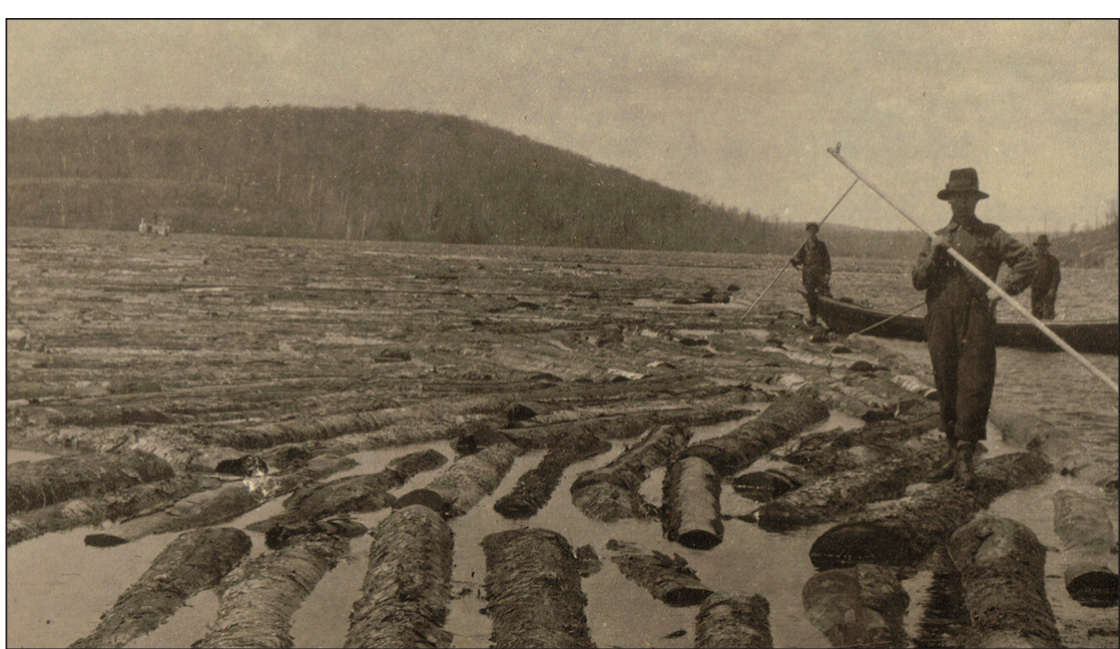

Men with pike pole pointers. Notice the alligator in the far left background.

Nancy Langston, a Professor and Environmental Historian at the University of Wisconsin-Madison, wrote a fascinating paper "Reflections: on Teaching World Forest History. (Environmental History 10:20-29.2005) After reading her paper, I dare anyone to say that their knowledge and understanding of forest history has not changed; to say that their appreciation of the depth and breadth of forest history has not been increased and to say they did not find her paper a fascinating read.

She summarized her paper by saying "History matters: it is not just about understanding the past, it is necessary for creating a better future."

She suggests that forest history is very broad and worthy of serious academic study; it is much more than just a collection of papers and artifacts. It also pertains to the cultural and economic impact of forestry on those working in the industry, on the development of public policy and the development of communities and regions and their social and cultural life. It also includes the broad aspects of forest ecology, and its associated fauna and flora life. As well, it includes the songs, poems and stories of the woods. In short, forest history is almost anything you want it to be.

With this introduction of how we view forest history let us now briefly review the three periods of saving and recording forest history. In each we will mention the major characteristics of the period and the resulting strengths and problems of each.

\section{The Past}

In the past forest history reflected a stable industry in which companies and operating groups remained in place for many years and changes were in general evolutionary. The printed page and photographs were the norm and these were stored in filing cabinets and storage boxes, which remained safely in place for many years. Changes in companies, work forces, technology, forest institutions and forest policy were evolutionary and there was development of corporate and institutional memories. One expected next year to be much the same as this year.

Thus, any proposed forest history project had probable access to written material, records, photographs and artifacts. As well, background recollections and knowledge were available from those "who had been there."

\section{The Present}

Today we have a different story. Starting about 20 years ago, the industry fell into a state of flux. In the Interior of British Columbia, the Mountain Pine Beetle began to drastically change the supply 
and type of log delivered to the sawmill. The collapse of the US lumber market and very serious economic problems in other parts of the world significantly reduced the market for lumber and other forest products and magnified the problems created by the Mountain Pine Beetle. As a result, mills amalgamated or closed, changed their milling and harvesting techniques, grew larger in size as each tried to achieve economies of scale, automation in the mills increased, and the number of workers decreased. In short, the company became "lean and mean."

Much work was contracted out. A contractor did a specific job and then left, leaving reports behind but taking most of the working papers and background material with him. The next time work was required, most likely another contractor would get the job. There was no corporate memory being developed and in many cases, no continuity of records.

Forest history projects started today can draw on the records saved from the past and the recollections and memories of the workers who were there. Much information was in files found in old storage areas, and in personnel files. However, this fund of information and material from the past is disappearing with time as files are lost or destroyed and "old timers" are no longer with us. The closer we get to the Present the more difficult it will be to find the records, information and people we need to preserve the past and to understand and appreciate the forest industry of today.

\section{The Future}

It is clear that the future will be quite different from the past. The younger generation is becoming more and more comfortable with digital records. Lap tops, e-books, iPads and smartphones are now common and the use of e-mail, Facebook, Twitter, and other social media are just a way of life for many people now.

Paper records are disappearing as computers become the usual working tool and workers are accustomed to using them. This has meant that more records are being created digitally and transmitted and stored electronically. This has many implications:

- Computer failures and hard drive crashes are common and often data stored on the drives are lost unless

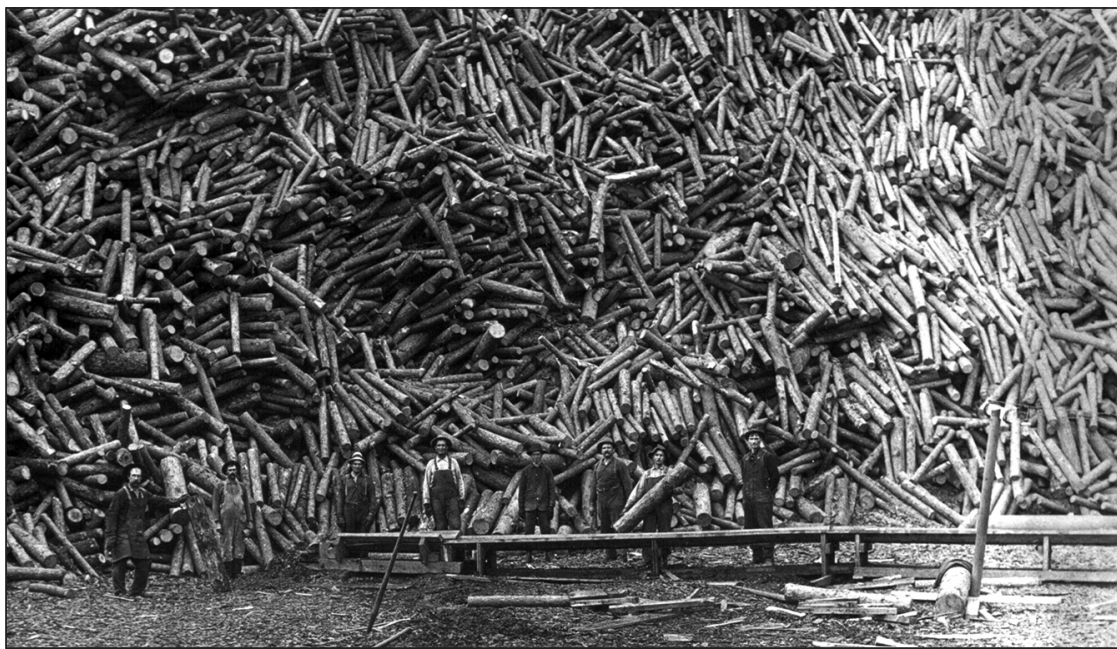

Eight men loading pulpwood early 1940s.

backup copies are created in a consistent way and on a regular basis.

- Computer programs and languages are constantly changing. Thus, the ability to read disks and hard drives is being lost through time and obsolescence. A common rule of thumb is that all records should be renewed every five years. How many people today remember Lotus 1-2-3 and WordPerfect and how many computers are able to read these programs?

- Computer storage disks are constantly changing (how many people remember floppy disks?) and old disks are easy to toss out.

- Computers are constantly being upgraded and the contents of drives and disks for the old units discarded.

- Computer drives and disks can hold vast amounts of data. It is easy to forget how much information is there. With drawers, filing cabinets or stacks of storage boxes there is more appreciation of what is there.

- Computer information and disks are very hard to review and assess. Unlike information stored in filing cabinets or storage boxes, you cannot readily review or assess them unless you have a means of opening and reviewing the files.

A major problem in saving archival information stored on computers is that computers are so new that techniques and knowledge to do so have not been fully developed or widely known. We have had hundreds of years of experience with paper and have the knowledge as to how it must be handled and stored. With digital information this knowledge base has not had a chance as yet to be fully developed and to become widely known. For most of us we are still feeling our way.

Professional archivists are keenly aware of the problems and are rapidly developing techniques, software programs and protocols to recognize, protect and save digital information. However, there will be a long learning curve between the users of the information on the hard drive and the professional archivists who know how to read, interpret and save the information. Companies and organizations, in fact all of us, must recognize the importance of information and learn how to best save and protect it. We must all talk with archivists, learn what is important and how to best save and protect it. It is clear that much of the information generated and saved on hard drives has little archival value. Learn to identify what is important. Talk with the people who can help you.

The digitization of information also has a positive feature. Many museums and archives are digitizing their collections and placing the information on the web. One can now access books, magazines, photographs, and papers through the web, which only a few years ago were available only in the holding institution. Now it is possible to screen photographic collections, read books, and search records in a way not possible in the past. Make use of this capability - enjoy the power you have at your fingertips.

Stan Chester FHABC 

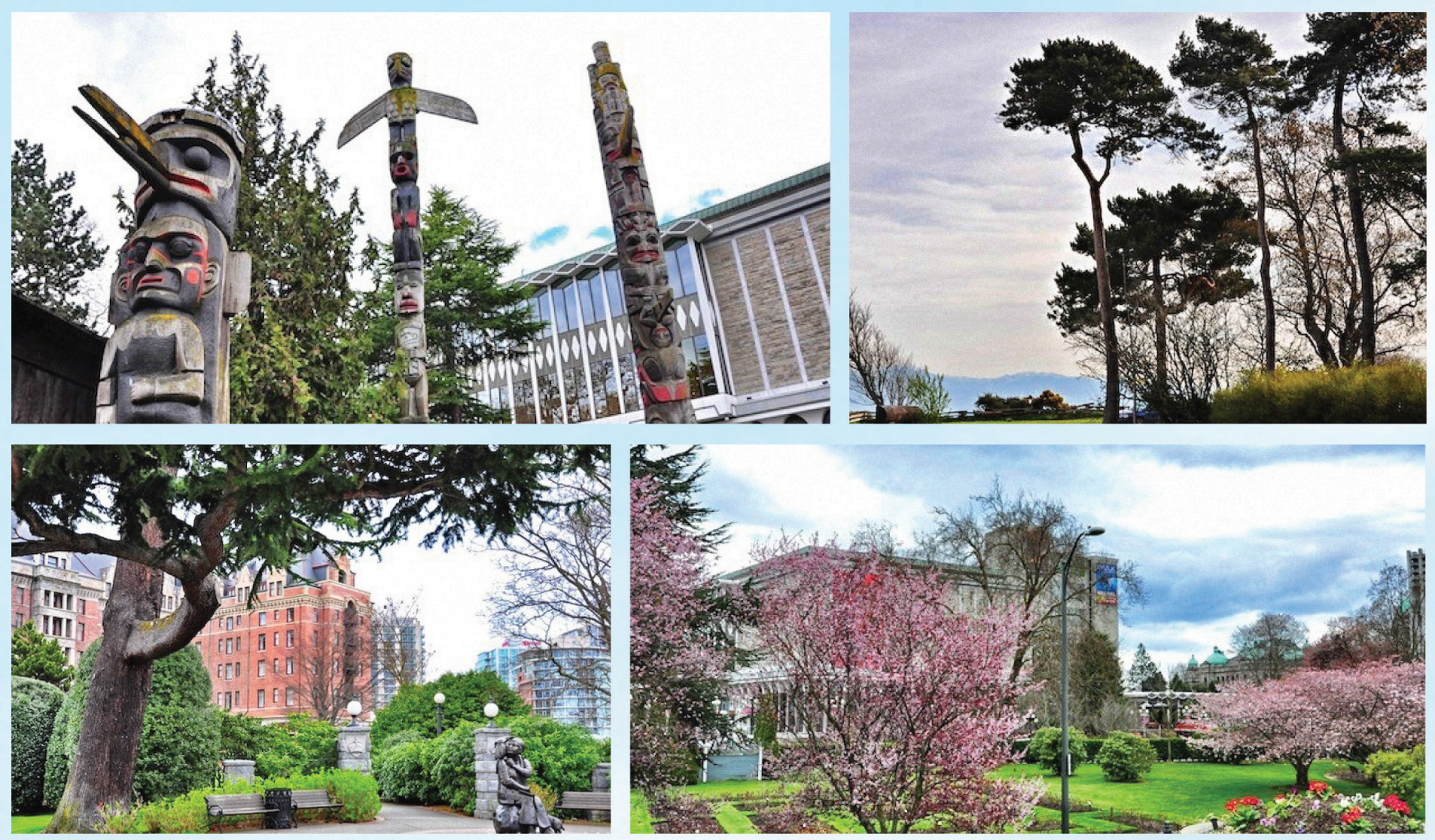

\title{
Canadian Urban Forest Conference
}

\section{Urban Forests by Design}

\section{Sept 30 - Oct 2, 2014}

\section{Victoria, British Columbia | Colombie-Britannique}

\author{
Register today! Inscrivez-vous maintenant!
}

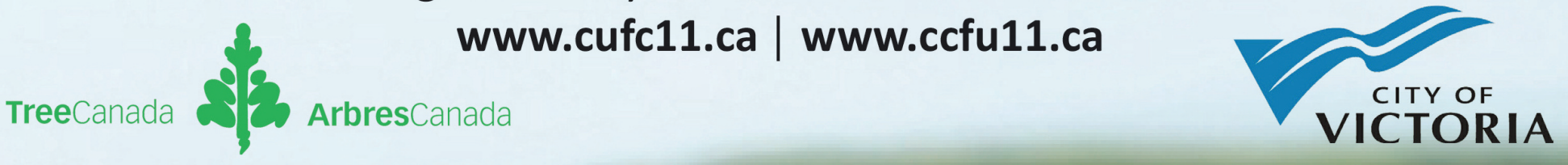

The Canadian Urban Forest Conference brings together leading experts from across the country in a bilingual setting and allows for dialogue between professionals and community groups on innovative strategies, policies, technologies, research, and best management practices. 